
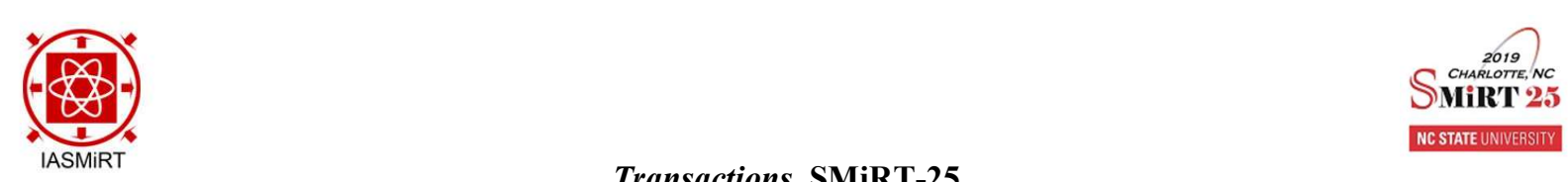

Transactions, SMiRT-25

Charlotte, NC, USA, August 4-9, 2019

Division XI

\title{
METHODS FOR FAILURE ASSESSMENT OF NPP PRESSURE BOUNDARY UNDER SEVERE ACCIDENT LOADING
}

\author{
Christoph Bläsius ${ }^{1}$, Jürgen Sievers ${ }^{2}$ \\ ${ }^{1}$ Expert Structure Mechanics, Gesellschaft für Anlagen- und Reaktorsicherheit (GRS), Germany \\ ${ }^{2}$ Chief Expert Structure Mechanics, Gesellschaft für Anlagen- und Reaktorsicherheit (GRS), Germany
}

\begin{abstract}
During postulated high-pressure core melt accidents, high temperatures can be reached in the reactor coolant system (RCS) pressure boundary due to hot gases from the core melt process, which may lead to failure of the pressure boundary in terms of a leak or a break. Location, time and mode of the failure can have large implications on the further accident progression. Nevertheless, not for all possibly affected components and failure modes suitable assessment methods, in-depth structure mechanical analyses or in some cases even simple models for the integration into severe accident codes are available.

This paper concentrates on assessment methods for gross boundary failure, e.g. of RCS piping. First, failure modes of components as well as the deformation and fracture behaviour of typical RCS materials in the severe accident loading regime are discussed. Established assessment methods based on linear damage accumulation and the use of Finite Element (FE) codes as well as a newly developed method based on a reduction to a 0 -dimensional element is presented. The methods are validated and compared on a largescale experiment of a DN700 pipe and international benchmark analyses within the OECD/NEA activity COSSAL (Components and Structures under Severe Accident Loading). Results of the application to a representative severe accident scenario in a PWR and parametric studies are summarized.
\end{abstract}

\section{INTRODUCTION}

In scope of reactor safety, the pressure boundary of the reactor coolant system (RCS) fulfils the function of a barrier for radioactive materials as part of the defence-in-depth safety concept. During postulated highpressure core melt accidents, the integrity of the pressure barrier is challenged by a combination of high inner pressure, maintained by Safety and Relief Valves (SRV), and high temperature due to heating by gases from the core melt process. These gases pass components of the RCS on their way into the containment and may also circulate through steam generator tubes due to natural circulation.

The first failing component, the exact location and the failure mode can determine the further course of the accident. A particular thread is posed by failure scenarios leading to bypass or damage of the containment, such as High Pressure Melt Ejection (HPME) and Direct Containment Heating (DCH), Consequential Steam Generator Tube Rupture (C-SGTR) or failure of large components, challenging the leak tightness of the containment by their destructive potential. Even in a favourable scenario, when the RCS is slowly depressurized by early leaks, the failure location can have a large impact on the thermal hydraulic situation in the containment including the release and dispersion of hydrogen and aerosols.

The phenomenon of RCS pressure boundary failure or specific failure modes therein are regularly assigned with high rankings in Severe Accident Phenomena Identification and Ranking Tables (PIRT) (Magallon et al. 2005, Schwinges et al. 2010). In the aftermath of the events in Fukushima Dai-ichi 2011, 
especially after the high-pressure core melt in unit 1, the phenomenon has become especially aware again (Klein-Heßling et al. 2014, Bunt et al. 2015, OECD/NEA 2015). Nevertheless, not for all possibly affected components and their related failure modes suitable assessment methods, in-depth structure mechanical analyses or in some cases even simple models for the integration into severe accident codes are available. Some recent progress on this topic can be found in (Sancaktar et al. 2018).

\section{FAILURE MODES AND MATERIAL BEHAVIOR UNDER SEVERE ACCIDENT LOADING}

Failure modes of the RCS pressure boundary under severe accidents differ from those under normal operation conditions. Based on prior work of (Kasahara et al. 2015) failure modes of metallic components under severe accident loading can be classified into gross boundary failure, local boundary failure and excessive deformations (Figure 1).

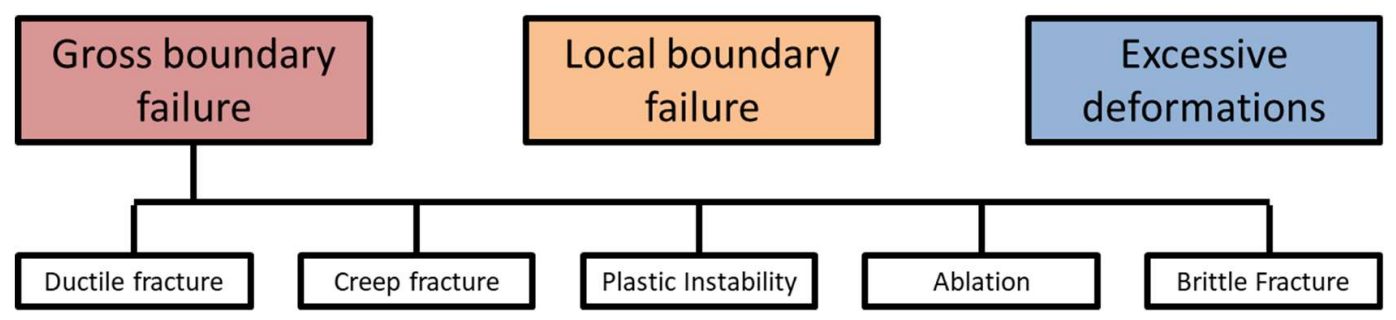

Figure 1: Failure modes, especially for gross boundary failure under severe accident loading

Gross boundary failure, which is considered in this paper, is characterized by a sudden large-area loss of integrity, e.g. after extensive ductile/creep deformation or excess of the temperature-dependent ultimate tensile strength (UTS) and subsequent plastic instability. Depending on the material microstructure, brittle fracture, e.g. due to material hot shortness, cannot be precluded (Sehgal 2012). It can be assumed that large components, such as RPV and RCS piping are generally prone to gross boundary failure in a severe accident.

Local failure results in a leak of limited size. In the basic case, it comprises the same failure modes except that the failure area is very limited due to focussed load or geometry. Additionally, failure at preexisting defects, cracks or leaks or the loss of traction or tight fit, e.g. in flanges, may result in a leak of limited size. Failure of SRVs in open-position can be also classified as local boundary failure, but failure modes are complex and may depend on the individual valve model (Sancaktar et al. 2018).

Excessive deformations include phenomena caused by non-linear relationships between geometry and loading, like (creep) buckling, collapse or just excessive deformation without any non-linearity.

In the specific load regime, materials used for the reactor pressure boundary show a time-dependent viscoplastic creep deformation behaviour. As creep is an umbrella-term for several time-dependent microstructural deformation and damage mechanisms, the extrapolation of creep data or the use of methods from lifetime analyses is not valid readily. In the loading range considered here, creep deformation is mainly driven by dislocation creep, which is similar to plastic deformation, except that diffusion instead of increased stress is the driver for dislocations passing obstacles (Ashby and Dyson 1984). Especially for RCS piping at elevated temperatures it is possible that plastic instability and macroscopic necking is reached before fracture of the material, since failure strains for typical reactor boundary materials can be high and increasing circumferential stress (due to ballooning) and decreasing UTS (due to temperature) converge rapidly. Estimations of failure strains based on area reductions for 20MnMoNi5-5 measured in (Klenk et al. 2005) using Bridgman-Formulas described e.g. in (Alves and Jones 1997) revealed failure strains of about $150 \%$ at $600{ }^{\circ} \mathrm{C}$ and $300 \%$ at $900{ }^{\circ} \mathrm{C}$. 
Material models are derived for ferritic carbon steel 20MnMoNi5-5, austenitic stainless steel 22NiMoCr3-7 and nickel-based alloy Incoloy 800 (mod.), each representing one group of RCS pressure boundary materials, containing thermomechanical, elastic, multilinear plastic and short-term creep data. The derivation of short-term creep data is shown in Figure 2 for the case of 20MnMoNi5-5 based on data from (Klenk et al. 1999, Klenk et al. 2005).
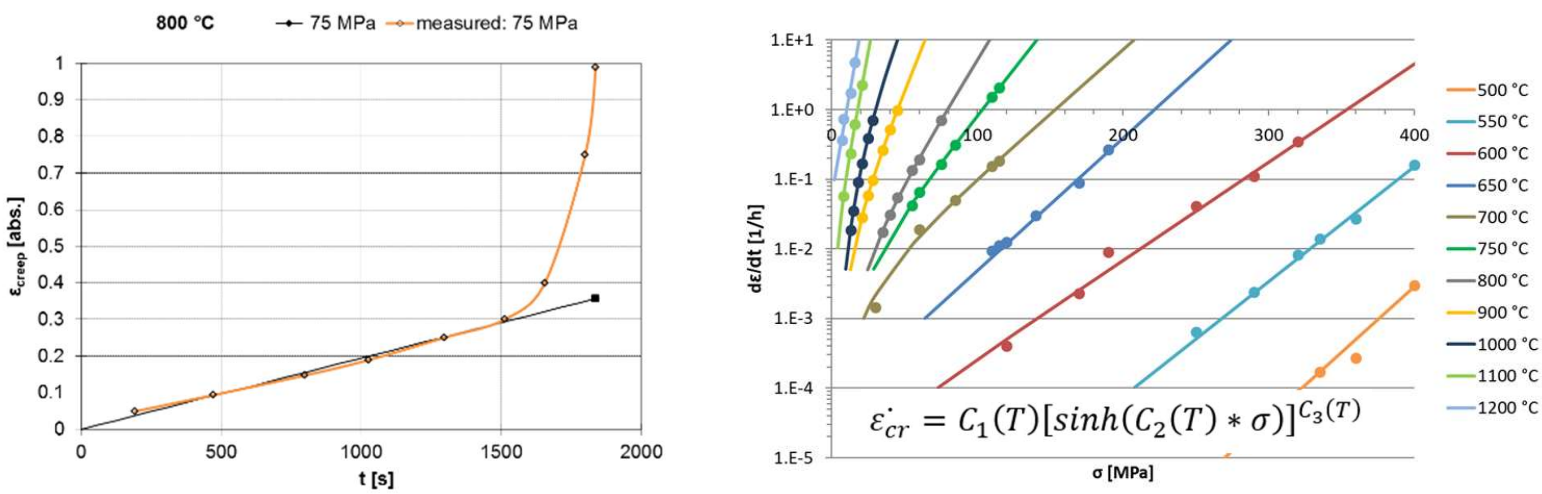

Figure 2: Derivation of short-term creep data for ferritic carbon steel 20MnMoNi5-5

In the short-term creep tests, only minimal primary creep was observed, which is in accordance with theory at high temperatures (Webster and Ainsworth 1994). Tertiary creep was observed only for large strains, where the influence on failure time would be small or failure already had happened by plastic instability. Furthermore, the few existing stress-controlled tests revealed that a large share of tertiary creep in load-controlled tests was due to macroscopic deformation (Klenk et al. 1999). Therefore, only the constant secondary creep rate is extracted (Figure 2, left hand side) and fitted to a modified Garofalo form (Figure 2, right hand side), which is known for well describing creep data over large stress intervals. Therein, $\varepsilon_{c r}$ is the secondary creep strain rate, $T$ temperature, $\sigma$ normal stress and $\mathrm{C}_{1}, \mathrm{C}_{2}$, and $\mathrm{C}_{3}$ are fitting constants.

\section{METHODS FOR ASSESSMENT OF GROSS BOUNDARY FAILURE}

\section{Linear Damage Accumulation}

Analytical methods based on linear damage accumulation are established for the assessment of RCS pressure boundary failure in Severe Accident analyses. A damage variable D, indicating failure for $\mathrm{D}>1$ is calculated, e.g. for a transient loading, by the summation of relations between time step length $\Delta t$ with constant load and current failure time $t_{\text {f }}$.

$$
D(t)=\sum_{i} \frac{\Delta t}{t_{f}}
$$

Particular shortcomings of this linear approach are that large deformations and stress increase due to creep ballooning, as well as plastic strains are not considered or have to be considered indirectly in creep properties, making the values dependent from the specific application case. For the determination of failure time, which is dependent on stress and temperature, in most cases a relation based on (Larson and Miller 1952 ) is used.

$$
t_{f}=10^{\left[\frac{P_{L M}(\sigma)}{T}-C\right]}
$$


where $\mathrm{P}_{\mathrm{LM}}$ is the Larson-Miller-Parameter, usually dependent on stress by some empiric relation, $\mathrm{T}$ the absolute temperature and $\mathrm{C}$ a constant. The relation is fitted to either real-scale experiments, short-term creep tests on standard specimens or corresponding Finite Element (FE) calculations. Similar, but less commonly used approaches for the determination of $\mathrm{t}_{\mathrm{f}}$ are the relation based on (Manson and Haferd 1958) or the interpolation from a pre-calculated matrix, which was proposed by GRS in (Eisert et al. 1993) allowing some larger degree of freedom for fitting. The latter one is referred to as CLASSIC in the method comparison section.

\section{Finite Element Approach}

Commercial off-the-shelf Finite Element Codes are generally applicable for failure assessment of pressurized components under severe accident loading and offer possibilities for a more detailed calculation and parametric studies. Nevertheless, due to the effort and the need for detailed material data, this method is seldomly used, e.g. in (Grebner and Sievers 2001, Hagihara and Miyazaki 2007, Brust et al. 2013).

\section{Fast Assessment of Symmetric Component Rupture Time (FAST)}

The idea of the newly developed method FAST is to reduce a component analysis, which is symmetric in geometry and loading to a 0 -dimensional element, but consider large deformations as well as plastic strains evolving during the accident (Figure 3, left hand side). For each time-step, current stress, elastic, plastic and creep strain increment and geometry are iteratively recalculated (Figure 3, middle). The method can be interpreted as a non-linear FE calculation with a mesh consisting of just one element. It can use the material models built for FE calculations. Approaches exist to include external primary loads or asymmetries along the wall thickness (temperature gradients or a dual-layer structure/cladding). In the latter case, the global strain is iteratively adapted until the average of the stress profile along the wall thickness meets the calculated global stress (Figure 3, right hand side).

The method execution is very fast and fills a gap between simple damage accumulation methods and complex finite element models. It is included in the tool ASTOR (Approximated Structural Time of Rupture) developed at GRS which bundles several methods for the assessment of component behaviour under severe accident loading (Bläsius, Heckmann and Sievers 2019).
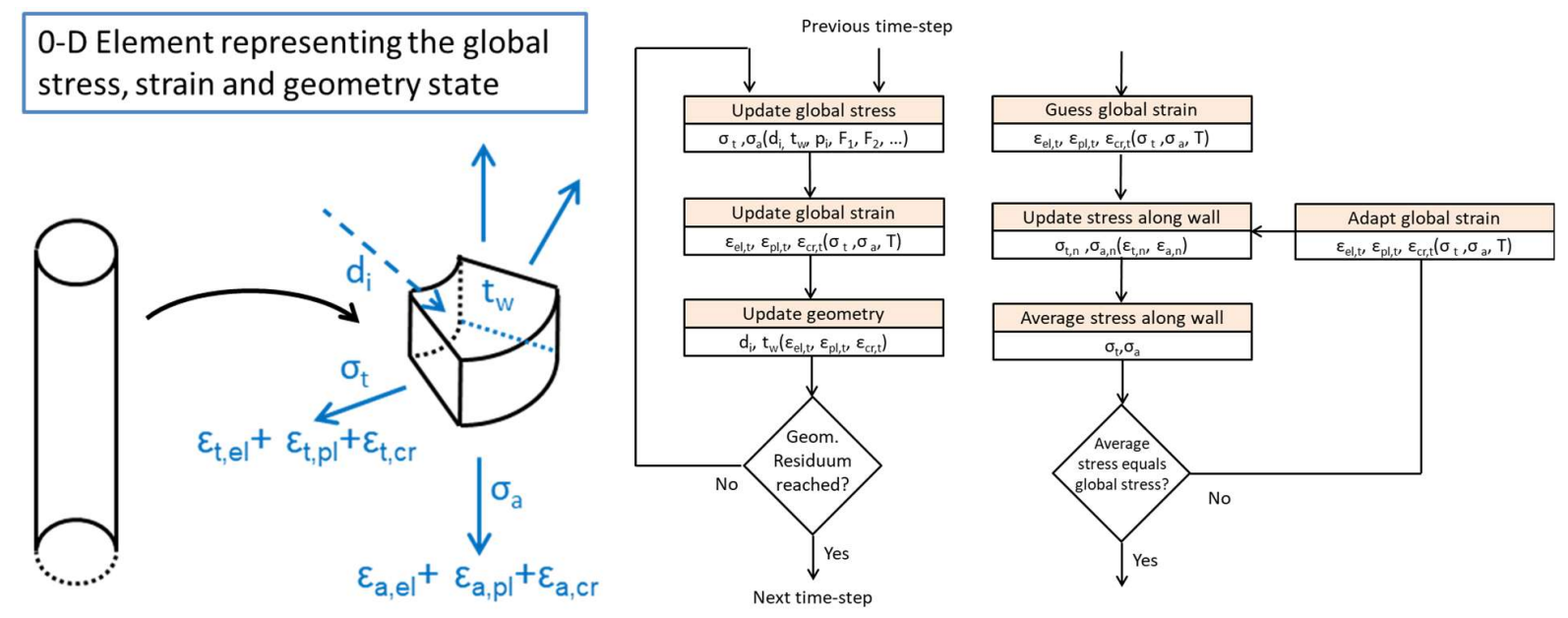

Figure 3: Principle idea of the method FAST (left hand side), calculation scheme (middle) and approach to include radial asymmetries by iterating global strain (right hand side) 


\section{COMPARISON ON A LARGE-SCALE EXPERIMENT AND BENCHMARK ANALYSES}

The presented methods are compared on a large-scale experiment, which was performed by the MPA University of Stuttgart (Maile et al. 1990). A test pipe with similar geometry, material (20MnMoNi5-5) and heat treatment as a straight section of a German PWR main coolant line, but without cladding, was welded together with auxiliary parts to a test assembly (Figure 4).

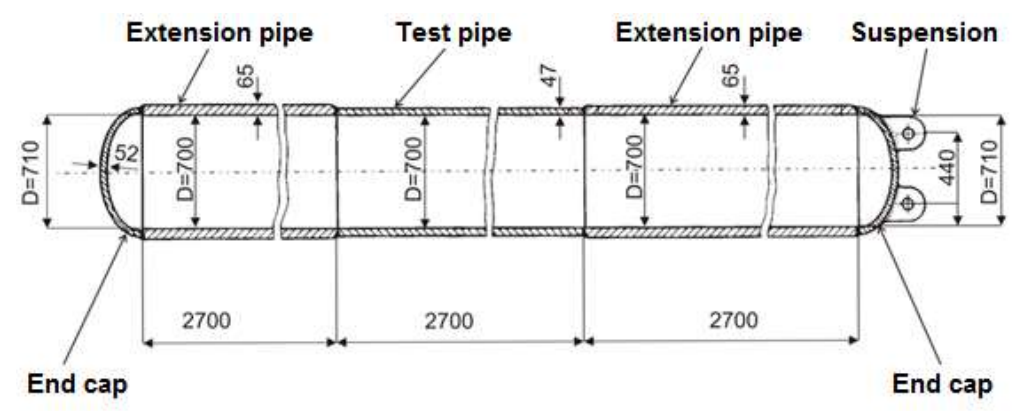

Figure 4: Geometry of the test specimen (Maile et al. 1990)

The geometric tolerance of the wall thickness was measured $\pm 0 \mathrm{~mm} /+0.3 \mathrm{~mm}$. Ultrasonic measurements did not reveal any defects. The specimen was fixed in an upright position freely suspended to a stiff structure. Inner pressure was applied by compressed air, temperature loading by inductive coils around the central test pipe, covered by an insulation layer. Figure 5 shows the measured internal pressure, temperature and radial deformation in the symmetry plane of the assembly with help of a clock face scheme.
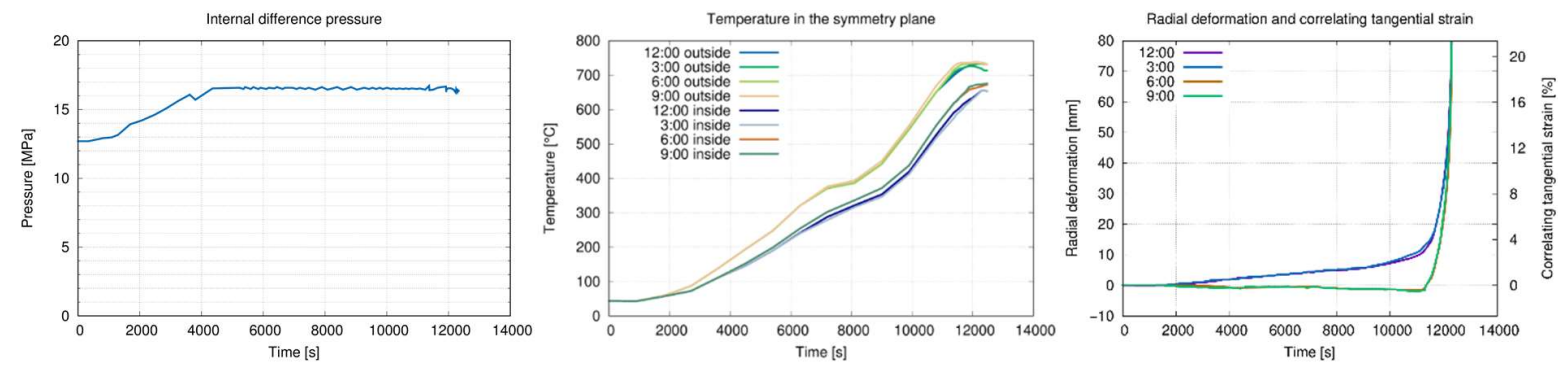

Figure 5: Internal pressure, temperature and radial deformation in the symmetry plane (Maile et al. 1990)

Table 1 lists the applied models and boundary conditions. The 2D model makes use of the almost symmetric load situation considering only the radial temperature gradient (Figure 6). Three different sets of thermal boundary conditions are used with the 2D model. A 3D model (Figure 7) takes the axial and circumferential temperature dependency into account. The temperature field is reconstructed from 32 temperature sensors in a two-step thermal calculation, calculating first the surface temperatures and then the temperatures within the volume. The model is fixed at one end in a way that deformations in radial and axial direction are not hindered. The mesh in radial direction along the temperature gradient is considerably coarser than for the 2D model for computational efficiency reasons. While the FE models and FAST could be supplied with the same material model, for the CLASSIC approach, data from (Arndt and Sievers 2011) adapted to the slightly different geometry, and for the Larson-Miller approach, data from (Bläsius et al. 2017) with units $\mathrm{MPa} / \mathrm{h} / \mathrm{K}$ are used.

$$
L_{M P}=7.9 e 3+\sqrt{2.3 e 8-9.3 e 7 * \log (\sigma)} ; \quad C=15
$$


Table 1: Methods employed for experiment recalculation

\begin{tabular}{|c|c|c|}
\hline Simulation & Model & Thermal boundary conditions \\
\hline 2D FE A & 2D model & Interpolation at failure initiation location in experiment \\
\hline 2D FE B & 2D model & Arithmetic average of the sensors in the symmetry plane \\
\hline 2D FE C & 2D model & Temperature of the sensor with global maximum \\
\hline 3D FE & 3D model & Detailed reconstructed temperature field \\
\hline LMP & Larson-Miller & Interpolation at failure initiation location in experiment \\
\hline CLASSIC & Matrix interpolation & Interpolation at failure initiation location in experiment \\
\hline FAST & FAST model & Interpolation at failure initiation location in experiment \\
\hline
\end{tabular}
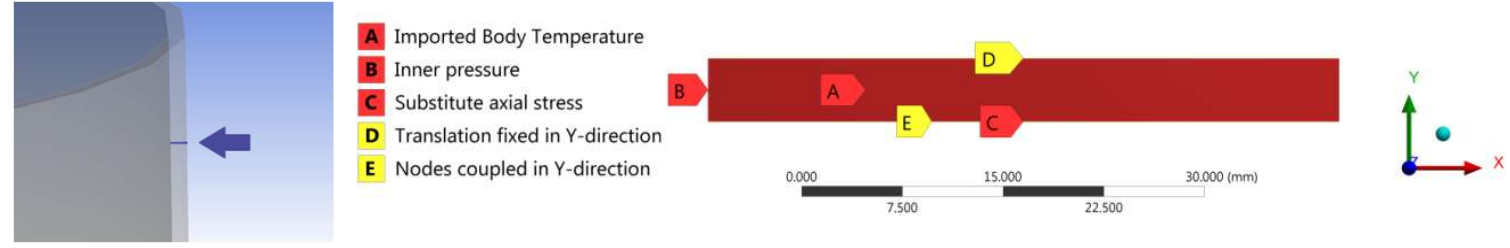

Figure 6: 2-dimensional axisymmetric model
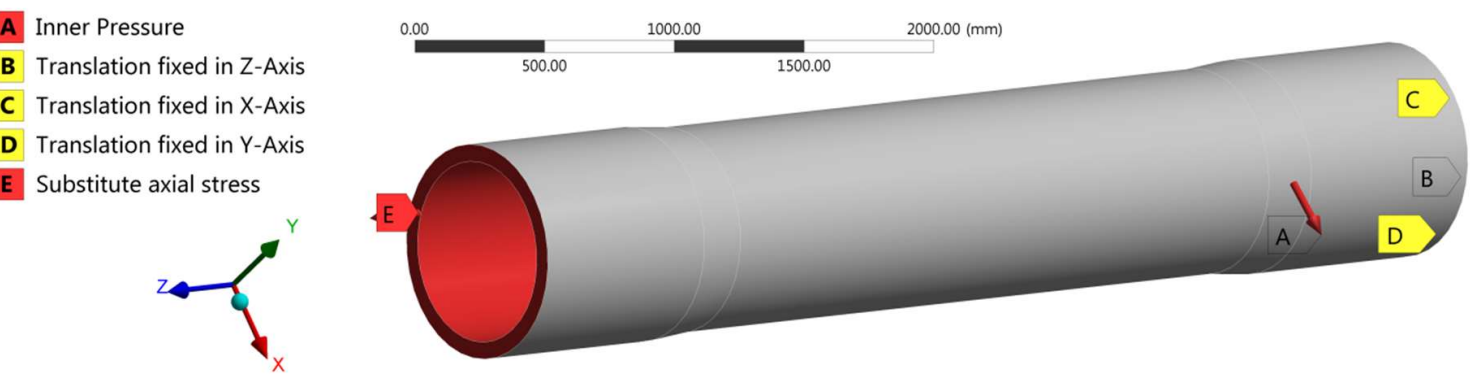

Figure 7: 3-dimensional model

Figure 8 depicts the measured and simulated radial deformations in the symmetry plane (see Figures 4 and 5). Up to $11000 \mathrm{~s}$ only small deformations due to thermal expansion are observed. Thereafter, deformation is driven by creep, until plastic deformation suddenly rises. The course reflects the strongly progressive nature of failure.

- The 2D calculations show that failure behaviour is very sensitive to the temperature boundary condition. As expected, calculation A with conditions at the observed failure location leads to an earlier failure than averaging the temperature-sensors in calculation $\mathrm{B}$. The choice of the temperature data of the sensor with the global maximum in calculation $\mathrm{C}$ does not show the earliest failure, as the whole temperature history in the creep-relevant time interval determines the final failure time. The comparison of the $2 \mathrm{D}$ calculations allows just a relative statement, since all values are within the magnitude of uncertainties in measurement and recalculation.

- The 3D model is in line with the 2D A calculation. Apart from the exact temperature field, the 3D model apparently takes into account the beginning changes in stress situation due to the change 
from cylindrical to spherical form in the centre of the pipe as well as the supporting effect of colder regions around hot spots. The radially asymmetric deformation of the experiment could not be reproduced and might be attributed to rigid body motion. Like observed in the experiment, the maximum of the deformation is slightly shifted in axial direction.

- The Larson-Miller (LMP) and the CLASSIC calculation of the Damage Parameter show an acceptable result, considering the method simplifications. The progressive failure characteristics, which is mainly due to large deformations and plasticity, could not be reproduced due to the linear approach. Damage starts to develop at temperatures, where FEM and FAST does not show any radial displacement yet.

- The FAST model shows a similar behaviour than the FE calculations, which indicates that the newly developed method covers the key-effects of piping gross boundary failure.

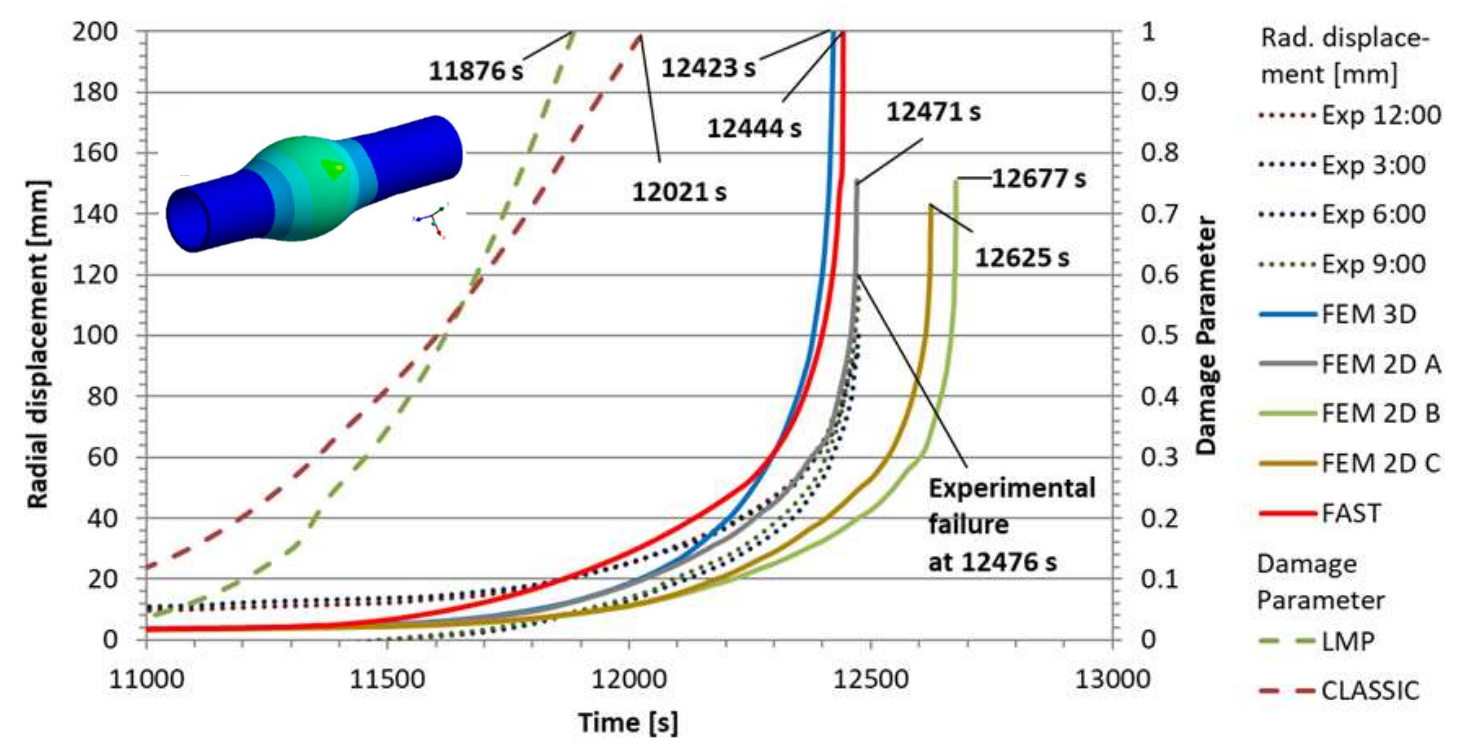

Figure 8: Measured and simulated radial displacement, deformation of the 3D model at failure (upper left in the diagram), calculated Damage Parameter, calculated failure times compared with measured value

International comparative calculations were done on the experiment within the OECD/NEA COSSAL benchmark activity of the CSNI (Committee on the Safety of Nuclear Installations) WGIAGE (Working Group on Integrity and Ageing of Components and Structures). The main objective was to quantify uncertainties in component integrity assessment under severe accident loading, especially in determination of failure time. The evaluation of the analysis results show that all participants met the experimental failure time and the course of the radial displacement within acceptable limits. A geometric non-linear calculation and a material law which considers non-linear material properties, i.e. creep and plastification effects has been shown necessary. Norton's Law, a modified Garofalo formulation and a Khachanov-Rabotnov-Law were successfully applied. More details can be found in (OECD/NEA 2019).

\section{APPLICATION TO A SEVERE ACCIDENT SCENARIO IN A PWR-1300}

The FE methods are applied to a station-blackout scenario in a PWR-1300 based on thermal-hydraulic calculations in (Köberlein et al. 2001). Around $10000 \mathrm{~s}$ after the beginning of the accident, the temperatures in hot leg, surge line and steam generator entrance sharply rise (Figure 9) with the onset of zirconium oxidation, while the other components remain at a rather low temperature. The inner pressure is almost constant at around 16.6 MPa. 


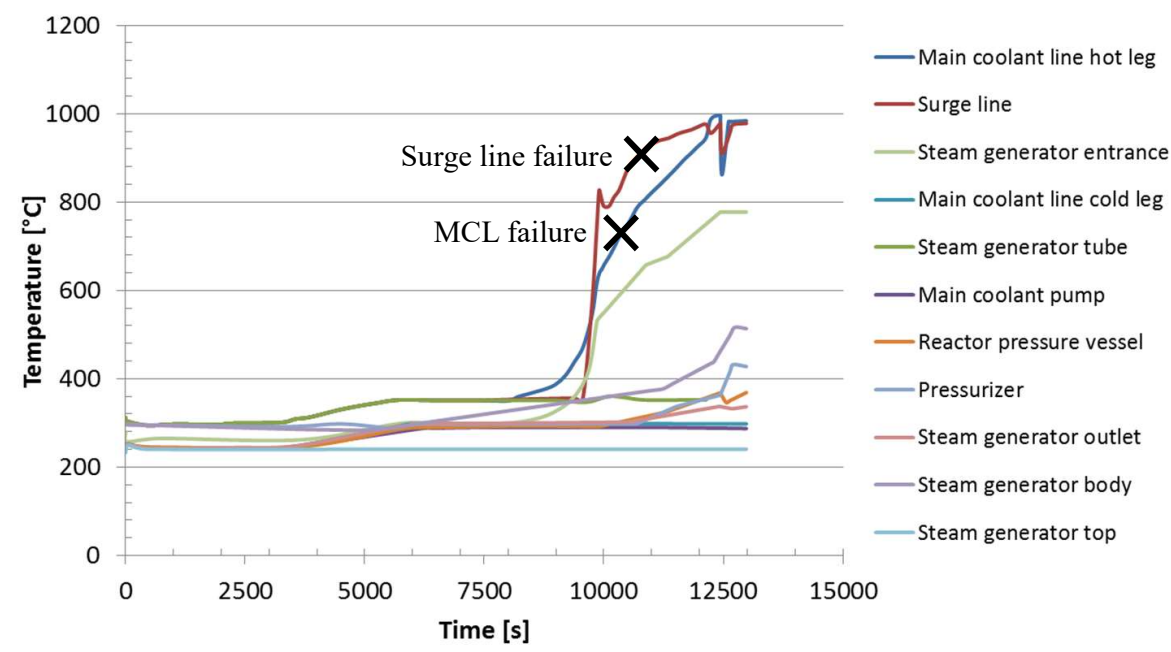

Figure 9: Temperature course of the components in a station-blackout scenario in a PWR-1300 based on thermal-hydraulic calculations (Köberlein et al. 2001) - Calculated failure times based on 3D FE

The 3D FE model consists of several components of the RCS of a PWR-1300, which are connected among themselves by rigid contacts (Figure 10). Some components, like the steam generator internals or the main coolant pump drive, are represented by point masses. The fixation of the model in space is guided by the real suspension behaviour, which has been validated against plant measurements of thermal elongation during temperature ramp-up in (Bläsius et al. 2017). The mesh is refined at locations where strong gradients are observed. The main components consist of ferritic carbon steel $20 \mathrm{MnMoNi5}-5$, the surge line of austenitic stainless steel X10CrNiNb18-9. The cladding is neglected in this step and its thickness is added to the base material. Thermal loads are applied globally on each component with transition areas between components. Mechanical loads in form of inner primary pressure, secondary pressure and gravity are applied. Apart from the base case simulation several parametric studies regarding different factors of influence are performed and results are listed in the following:

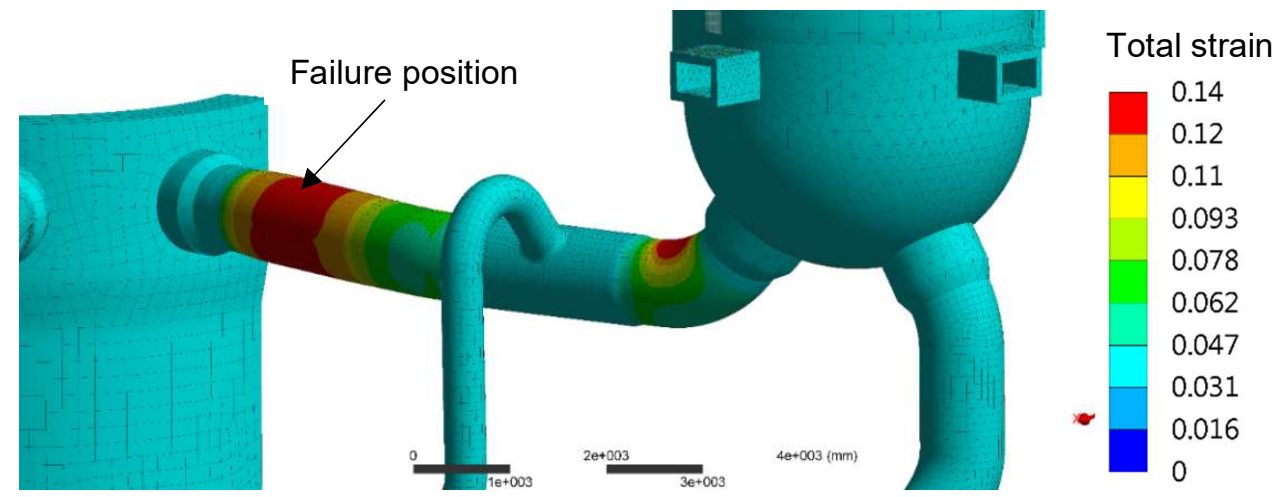

Figure 10: Distribution of total strain in the 3D model shortly before failure (deformations in real scale)

- The failure of the main coolant line straight section near RPV is calculated at $11100 \mathrm{~s}$ (Figure 9).

- Although having a higher temperature, failure of the surge line is predicted $12 \mathrm{~min}$. later due to the smaller ratio of radius to wall thickness and the more temperature resistant material.

- If only plasticity is considered instead of plasticity and creep, a $7 \mathrm{~min}$. later failure is observed. 
- If large strains are not considered, an $8.5 \mathrm{~min}$. later failure is observed. The evaluation of the failure time then becomes difficult, since the clear asymptotic course of strain at failure time disappears and a finite strain (here 0.3 ) has to be determined as failure criterion.

- The influence of the interaction between components from thermal elongation might be neglected, as secondary stresses relax with creep before significant plastic strains are accumulated. Geometry changes, e.g. in form of ovalization, from external displacements showed no significant effect.

- Gravitational loads are shown almost negligible for the cooling loop model.

- Temperature rise due to the released deformation energy is analytically calculated $5 \mathrm{~K}$ for 0.2 total deformation under adiabatic conditions, which means a limited effect on failure acceleration

- The consideration of the cladding showed a 1 min. later failure in a 2D FE model of the main coolant line, if the cladding is modelled separately and from austenitic stainless steel instead of adding its thickness to the base material thickness.

- Interactions of the large components with lateral barriers, e.g. earthquake vibration damper, revealed no influence, since strains accumulate in the elbows that have a larger diameter than the straight pipe and stresses relax at higher temperatures.

The integrity of the steam generator tubes was assessed for a similar accident scenario in (Arndt, Bläsius and Sievers 2017). Taking into account the time difference in the onset of zirconium oxidation and the corresponding temperature rise, the failure of steam generator tubes prior to other components of the RCS cannot be precluded, especially for tubes with pre-damage.

\section{CONCLUSION}

In the paper, established assessment methods for gross boundary failure and the newly developed method FAST based on a 0 -D element approach are presented. The methods are validated and compared to a largescale experiment of a DN700 pipe. All methods could reproduce the failure time within an acceptable time interval. FEM and FAST could reproduce the deformation behaviour and failure time better due to a more sophisticated material model as well as the explicit consideration of large deformations and plastic strains. Parametric studies on the application case of a station-blackout scenario showed among other factors of influence that the interaction between components due to thermal elongation might have only a negligible effect on failure. Combining the results with past analyses, the failure of steam generator tubes prior to other components of the RCS cannot be precluded, especially for tubes with pre-damage.

Future research may focus on local failure of pressurized components, components with pre-damage and early leaks. With improving Computational Fluid Dynamics capabilities, more detailed loading assumptions can be made available for structure mechanical analysis.

\section{ACKNOWLEDGMENT}

This work was performed in the framework of the German Reactor Safety Research and was funded by the German Federal Ministry of Economic Affairs and Energy (BMWi, project no. RS1555).

\section{REFERENCES}

Alves, M., Jones, N. (1997). "Influence of hydrostatic stress on failure of axisymmetric notched specimens", Journal of the Mechanics and Physics of Solids, Vol. 47, pp. 643-667

Arndt, J., Sievers, J. (2011). "Failure Assessment Methodology for Piping Under High Temperature and Pressure due to Creep and Plastification", Transactions of the SMiRT-21, New Delhi, India

Arndt, J., Bläsius, C., Sievers, J. (2017). "Analysis Methods for Integrity Assessment of Steam Generator Tubes under High Temperature and Pressure Loads", Transactions of the SMiRT-24, Busan, Korea 
Ashby, M.F., Dyson, B.S. (1984). "Creep Damage Mechanics and Micromechanism”, Proceedings of the 6th International Conference on Fracture ICF6

Bläsius, C., Arndt, J., Bahr, L., Sievers, J. (2017). Behaviour of components under beyond design loading, GRS - 459, in German

Bläsius, C., Heckmann, K., Sievers, J. (2019). "Quality Management, Verification, and Validation of Structure Mechanical Computer Codes at GRS", Transactions of the SMiRT-25, Charlotte, NC, USA

Brust, W., Iyengar R., Benson, M., Rathbun, H. (2013). "Severe accident condition modeling in PWR environment: Creep rupture modelling", Proceedings of the ASME 2013 PVP Conference, Paris, France

Bunt, R. et al. (2015). "Reactor Safety Gap Evaluation of Accident Tolerant Components and Severe Accident Analysis", Proceedings of the NURETH-16 Conference, Chicago, IL, USA

Eisert, P., Gruner, P., Kuntze, W.M. (1993). "Estimation of Lower Head Failure Times Using the Method ASTOR", Transactions of the SMiRT-12

Grebner, H., Sievers, J. (2001). "Limit load of a PWR coolant loop for a hypothetical core melt scenario with high temperature and high pressure", 27. MPA-Seminar, Stuttgart, in German

Hagihara, S., Miyazaki, N. (2007). "Finite element analysis for creep failure of coolant pipe in light water reactor due to local heating under severe accident condition", Nuclear Engineering and Design, Vol. 238, pp. 33-40

Kasahara, N., Nakamura, I., Machida, H., Nakamura, H. (2015). "Identification of failure modes under design extension conditions", Proceedings of the ASME 2015 PVP Conference, Boston, MA, USA

Klein-Heßling, W. et al. (2014). "Conclusions on Severe Accident Research Priorities", Annals of Nuclear Energy, Vol. 74, pp. 4-11

Klenk, A., Stumpfrock, L., Schemmel, J., Schellenberg, G. (1999). Determination and modeling of the material behavior of reactor steels under multiaxial stress loading for the design exceeding temperature range of $400{ }^{\circ} \mathrm{C}$ to $1000^{\circ} \mathrm{C}$, MPA Stuttgart, in German

Klenk, A., Ringel, M., Stelling, O. (2005). Description of the short-term creep behavior at design exceeding temperatures up to $1200^{\circ} \mathrm{C}$ on the basis of damage mechanisms, MPA Stuttgart, in German

Larson, F.R., Miller, J. (1952). “A Time-Temperature Relationship for Rupture and Creep Stresses”, Trans. ASME, Vol. 74, pp. 765-775

Maile K., Klenk, A., Obst, V., Sturm, D. (1990). “Load carrying behaviour of the primary system of PWR's for loads beyond the design limits", Nuclear Engineering and Design, Vol. 119, pp. 131-137

Manson, S.S., Haferd, A.M. (1958). "A linear Time-Temperature Relation for Extrapolation of Creep and Stress-Rupture Data", National Advisory Committee for Aeronautics, Technical Note 2890

Magallon, D. et al. (2005). "European expert network for the reduction of uncertainties in severe accident safety issues (EURSAFE)", Nuclear Engineering and Design, Vol. 235, pp. 309-346

OECD/NEA (2015). Benchmark Study of the Accident at the Fukushima Daiichi Nuclear Power Plant (BSAF Project), NEA/CSNI/R(2015)18

OECD/NEA (2019). Components and Structures under Severe Accident Loading (COSSAL), Benchmark of the OECD/NEA CSNI WGIAGE, NEA/CSNI/R(2019)2

Sancaktar, S., Salay, M., Iyengar, R., Azarm, A., Majumdar, S. (2018). Consequential SGTR Analysis for Westinghouse and Combustion Engineering Plants with Thermally Treated Alloy 600 and 690 Steam Generator Tubes, US-NRC, NUREG-2195

Schwinges, B. et al. (2010). "Ranking of Severe Accident Research Priorities", Progress in Nuclear Energy, Vol. 52, pp. 11-18

Sehgal, R. (2012). Nuclear Safety in Light Water Reactors: Severe Accident Phenomenology, First edition, ISBN 978-0-12-388446-6

Verstegen, C., von Linden, J., Löffler, H., Müller-Ecker, D., Köberlein, K. (2001). Assessment of the accident risk of advanced pressurized water reactors in Germany, GRS-175, in German

Webster, G.A., Ainsworth, R.A. (1994). High Temperature Component Life Assessment, Chapman \& Hall, London, GB 